\title{
Archimedes, Vitruvius and Leonardo: The Odometer Connection
}

\author{
Massimo Callegari, Stefano Brillarelli, Cecilia Scoccia \\ Department of Industrial Engineering \& Mathematical Sciences, Polytechnic University of Marche, Ancona, Italy \\ Email:m.callegari@univpm.it, s.brillarelli@pm.univpm.it,c.scoccia@univpm.it
}

How to cite this paper: Callegari, M., Brillarelli, S., \& Scoccia, C. (2020). Archimedes, Vitruvius and Leonardo: The Odometer Connection. Advances in Historical Studies, 9, 330-343.

https://doi.org/10.4236/ahs.2020.95025

Received: October 30, 2020

Accepted: December 5, 2020

Published: December 8, 2020

Copyright $\odot 2020$ by author(s) and Scientific Research Publishing Inc. This work is licensed under the Creative Commons Attribution International License (CC BY 4.0).

http://creativecommons.org/licenses/by/4.0/

\begin{abstract}
A multimedia exhibition in Fano (I) in 2019 celebrated the tight links between Vitruvius and Leonardo on the 500th year since Leonardo's death. The authors realized an interactive animation of some machines to let the visitors enjoy an immersive experience of the studies of the great scholars of the past. They also took the opportunity to review the history of the odometer and to study how Leonardo redesigned the concept of Vitruvius. A few questions are still unanswered, but the search drove them back to another great scientist of the past, Archimedes of Syracuse.
\end{abstract}

\section{Keywords}

History of Machines, Mechanisms, Leonardo, Vitruvius, Archimedes, Odometer

\section{Introduction}

\subsection{The Odometer}

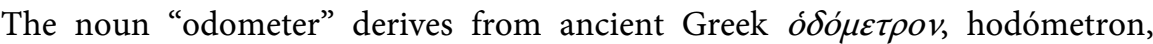
from ó $\delta o ́ \varsigma$, hodós ("path" or "gateway") and $\mu \varepsilon \dot{\varepsilon} \tau \rho o v$, métron ("measure") and identifies an instrument that has the purpose of measuring the distance travelled by a vehicle on land or at sea. The large majority of odometers are nowadays electronic or electromechanical but in ancient times they were purely mechanical. Designs have evolved over the years, but the basic function was always the same. They have always been used to measure distance in things like automobiles, see Figure 1, bicycles, and back before these were invented, horse drawn carts.

Possibly the first evidence for the use of an odometer can be found in the works of the ancient Greek Strabo (64 - 63 BC-24 AD) and the ancient Roman 


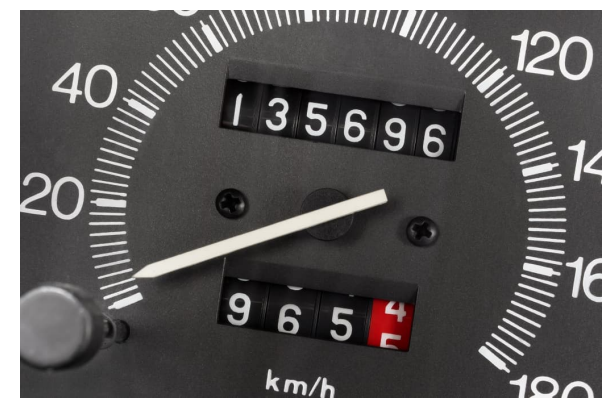

Figure 1. An odometer and a trip meter installed in a modern car.

Pliny (23 - $79 \mathrm{AD}$ ). Both authors list the distances of routes traveled by Alexander the Great (356 - $323 \mathrm{BC}$ ) as by his bematists Diognetus and Baeton: bematists were trained to measure distance while counting their steps but the high accuracy of the bematists' measurements rather indicates the use of a mechanical device. In fact from the nine surviving bematists' measurements in Pliny's Naturalis Historia eight show a deviation of less than $5 \%$ from the actual distance, three of them being within 1\%: the overall accuracy of the measurements implies that the bematists already must have used a sophisticated device for measuring distances, although there is no direct mention of such a device.

The first descriptions of this instrument have reached us through the manuscripts of the Roman architect and military engineer Marcus Vitruvius Pollio (80 - $15 \mathrm{BC}$ ). Around 30 - $15 \mathrm{BC}$ he wrote the famous "De architectura" dedicated to his patron, the emperor Caesar Augustus (Vitruvius, 1990): it is a ten books treatise meant as a guide for realizing projects such as buildings, military camps, facilities, instruments and machines. The odometer described by Vitruvius will be deeply explained in the next section.

As a matter of fact, the odometer has been studied by many scholars throughout history: Hero of Alexandria (10 - $70 \mathrm{BC}$ ) described an odometer set in motion by the rotation of a cart's wheel and Leon Battista Alberti in the mid-fifteenth century studied this instrument in the treatise "Ludi rerum mathematicarum". Between 1500 and 1504 Leonardo da Vinci (1452-1519) too was interested in the design of the odometer and drew few sketches on folio 1 of the Atlantic Codex preserved today in the Veneranda Biblioteca Ambrosiana in Milan.

In the following centuries prototypes of odometers have been built by many other scientists and inventors, such as Blaise Pascal (1623-1662) who used the same concept for the calculating machine called "Pascaline", Thomas Savery (1650-1715) who perfectioned an odometer for ships, Benjamin Franklin (17061790) who created a simple odometer to help measure the mileage of the routes when he decided to analyze the best routes for delivering the mail and many others.

In the end, it must be noticed that the odometer was also independently invented in ancient China (Needham, 1965) possibly by the prolific inventor and early scientist Zhang Heng (78 AD - 139 AD) or by the later Ma Jun (active during 220 - $265 \mathrm{AD}$ ); despite such associations, there is evidence to suggest that the 
invention of the odometer was a gradual process in Han Dynasty China that centered around the huang men court people (i.e. eunuchs, palace officials, attendants and familiars, actors, acrobats, etc.) that would follow the musical procession of the royal "drum-chariot".

\subsection{The Odometer within the Evolution of Design Theory}

Mechanisms design today is a process of creation, invention and definition, involving an eventual synthesis of contributory and often conflicting factors. Design rules and concepts were practiced extensively by the engineers of ancient times leading to machine design from machine elements to the design of a machine as a system.

In fact, since ancient times, many scientists and inventors have contributed to the study of mechanisms and machines. Most of them where Hellenic, Byzantines or Arabic. Originally, this kind of machines have been developed for practical requirements and then improved, using precise scientific concepts. For instance, the lever and the wedge have been used in various forms, even centuries before Archimedes was born (Dimarogonas, 1991): levers appeared in 5000 BC as a simple balance scale and in $3000 \mathrm{BC}$ a shaduf in Mesopotamia, using a lever system, allowed an operator to fill a bucket with water.

The first mathematical approaches to mechanisms design date back to the third century BC, developed by great scholars such as Ctesibius, Philo, Hero of Alexandria and Archimedes of Syracuse (Chondros, 2007, 2009). Their interest was generally devoted to war machines, such as ballistae, catapults, burning glasses, steam cannons and giant claws. As is well known, Leonardo da Vinci himself paid much attention to this type of mechanism and the strength of materials. There are many examples of this in the Codex Atlanticus and in his studies based on the De architectura of Vitruvius (Oliveira, 2019). The most iconic are winches, flying machines, machine guns, aerial screws, cranes and revolving bridges. But speaking about Leonardo's studies, it cannot be skipped his vision about programmable automation shown in the concepts of the Lion, the Knight and the Bell's Ringer, as reported in the Codex Madrid I and II (Rosheim, 2006).

Interesting surveys on machine designs of the Renaissance period can be found in (Ceccarelli \& De Paolis, 2008; Rossi et al., 2011; Cigola \& Ceccarelli, 2016): by using drawings reproducing Vitruvius's machines from Book X of his De Architectura (e.g. the editions by Fra' Giovanni Giocondo in 1513, Cesare Cesariano in 1521 and Daniele Barbaro in 1584) they analyze machine designs and drawings, both as an interpretation of Roman machines and inspiration for Renaissance designs.

One of the most important "enabling technology" for the development of modern design theory was certainly gearing systems, born during the Hellenistic period: Cicerone in De Re Publica mentioned a cycloidal gearwheel, stating that it had been built by Archimedes. Screw theory seems to be the common thread that has linked many of the studies conducted by Archimedes, Vitruvius and 
Leonardo da Vinci (in the Modern Era) (Chondros, 2010).

The gearwheel coupling was largely used for war machines, astronomical devices for the estimation of the position of celestial bodies and also odometers. One of the most important examples of the gear coupling is the mechanism of Antikythera, whose distinctive feature was the triangular shape of the teeth (Sorge, 2012). In this mechanism only one tooth pair is in contact at each instant. A series of studies have been performed to understand its operating conditions, e.g. De Solla Price (1974) and later Wright (2005) reconstructed the planetary system.

With triangular teeth, motion transmission is continuous but the speed ratio is variable: because of the higher velocity of the teeth during approach with respect to recess, an impact occurs at the beginning of the meshing phase. The gearing behavior was certainly characterized by a sensible rattling noise due to the teeth collisions and the energy losses were relevant but with a rudimentary lubrication the contact might be good enough.

As shown in the following sections, Sleeswyk (1981) built a prototype of the Vitruvius odometer in which replaced the square-toothed gear designs of da Vinci with the triangular, pointed teeth found in the Antikythera mechanism: with this modification, the Vitruvius odometer could work.

\subsection{The Fano Exhibition}

Notwithstanding the fact that Leonardo and Vitruvius have lived 1500 years apart, the connection between these two great scientists is strong and interesting even if little studied yet (Borgo, 2019): at the time of Leonardo the treatise of Vitruvius was already printed but hardly accessible, moreover it was written in Latin and without illustrations; however we know that it influenced the work of Leonardo very much throughout his life.

Among the first translators of Vitruvius' De Architectura there is certainly Francesco di Giorgio Martini, well known by Leonardo. He published several collections of mechanical drawings, one of which was found in Leonardo's library and marked up by him. The odometer uses a couple of speed changing mechanisms that can be found in earlier work of di Georgio as well as the so-called "anonymous Florentine artist". These drawings can be found in the work of Gustina Scaglia (1992).

Another good connoisseur of Vitruvius' work was Giacomo Andrea da Ferrara, Leonardo's fraternal friend. After the French occupation of Milan in 1500, Giacomo Andrea was beheaded for remaining faithful to Ludovico il Moro. On his return to the city, eight years later, Leonardo insisted on looking for the copy of Vitruvius that had belonged to Giacomo Andrea, evidently because it was full of drawings and annotations.

It has been noted already that most Renaissance scholars and artists were interested in Vitruvius' studies about architecture and painting techniques but Leonardo, on the other hand, drew on Vitruvius' work on issues related to hy- 
draulics, machines, measurement instruments, materials, and so on (Cigola \& Ceccarelli, 2014).

On the celebrations for the 500th year since Leonardo's death, the city of Fano (where Vitruvius was probably born) organized an exhibition on the work of Leonardo to put in evidence the influence of the previous studies of Vitruvius. Among the original drawings that were exposed, some sheets showed the design of three machines originally described by Vitruvius and then re-interpreted by Leonardo: the Water Clockwork, the Giant Crossbow and the Odometer.

The authors realized a digital reconstruction of the works by Leonardo and Vitruvius, with the aim to let the visitors understand the operation of such machines (Brillarelli et al., 2020). In fact, through an image wall and a motion capture system (see Figure 2), the visitors could interact with the digital models and explode the main components of the machines, zoom in or out the key mechanisms while in motion and see the machines while in operation within their natural environments. In the meantime, the availability of the digital models allowed the authors to explore the feasibility of the concepts, to assess the possible performance and to study the differences in the designs. This article illustrates how the two scientists developed the concept of the odometer and tries to put into evidence the differences between their works.

In the end it cannot be neglected that there is an earlier publication on Leonardo's machines edited by Mario Taddei et al. (2005), that also has wonderful illustrations of modern CAD interpretations of Leonardo's drawings, that includes the odometer. All these recall the work of the Italian Roberto A. Guatelli who made a set of 200 models for the IBM Museum in the mid 20th century.

\section{Vitruvius' Odometer}

Vitruvius describes two versions of the odometer in chapter 9 of book X of " $D e$ Architectura": one for measuring marine distances and the other for land travels, which is the one that will be commented here. Before turning to Vitruvius' odometer, it is useful to briefly recall the most important measurement units used in ancient Rome: the "foot", corresponding to $296.4 \mathrm{~mm}$; the "double step", which was 5 feet long or $1482 \mathrm{~mm}$; the "mile", corresponding to 1000 double steps (the word mile derives from the Latin expression "millia passuum"), which was therefore equal to $1482 \mathrm{~m}$.

Vitruvius' odometer, Figure 3, is driven by one of the two rear wheels of a four-wheeled carriage, called "raeda". The wheels have a diameter of 4 feet (about 1.2 meters) which roughly corresponds to a circumference of 12.5 feet; therefore it requires 400 turns of the wheels to measure the distance of 1 mile.

With reference to Figure 4, Vitruvius reduces the 400 turns of rotation of the wheels to the single turn of a shaft using the coupling between a single tooth integral with one of the rear wheels (1) and a gear wheel with 400 teeth placed on a vertical plane (2). The latter in turn has only one tooth on its internal face: such tooth meshes with a third gear wheel (3), laid on a horizontal plane. With 
each complete rotation of the gear wheel (2), the tooth integral with it advances the wheel (3) by one position. So every 400 rotations of the cart wheels, this has travelled 5000 feet, that is one mile, the 400 tooth wheel (2) has made a complete rotation and the upper disk (3) has rotated by one position.

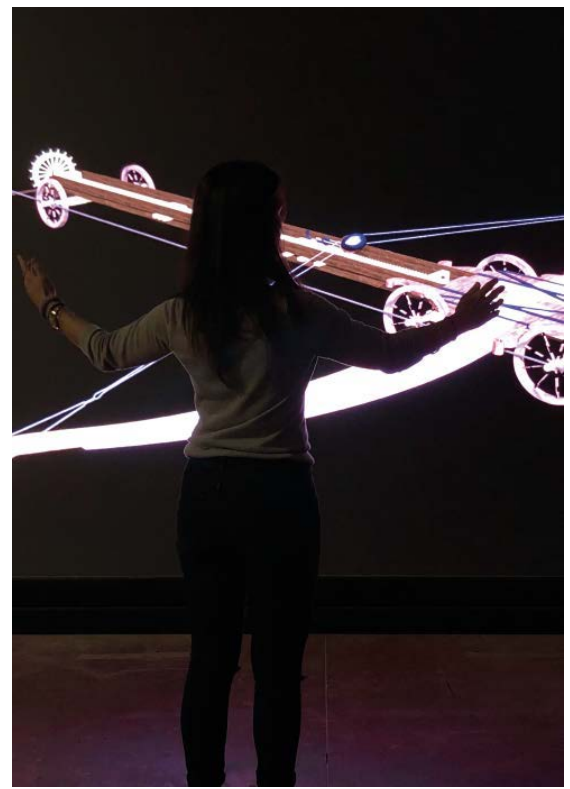

Figure 2. A visitor exploiting the digital mock-up of the giant crossbow of Leonardo at the image wall.

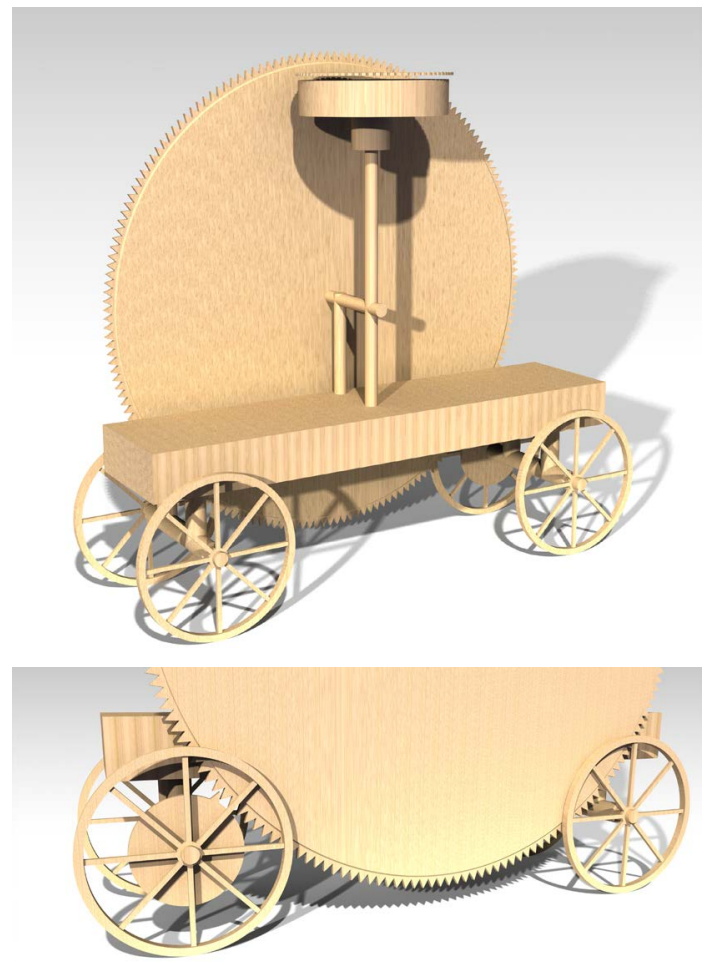

Figure 3. Reconstruction of Vitruvius' odometer according to Schofield (2016) (a 180 teeth gear is represented for sake of readability). 

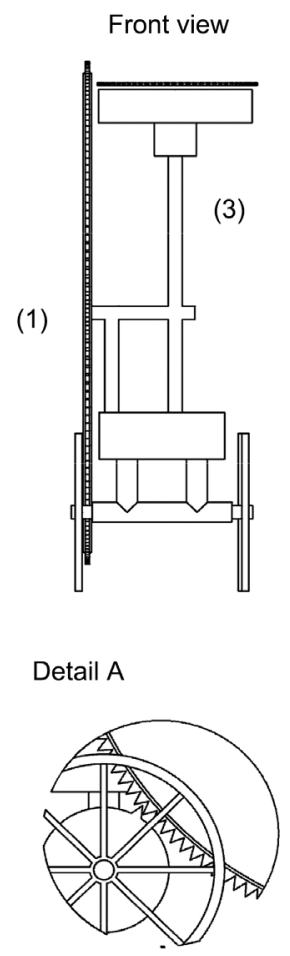

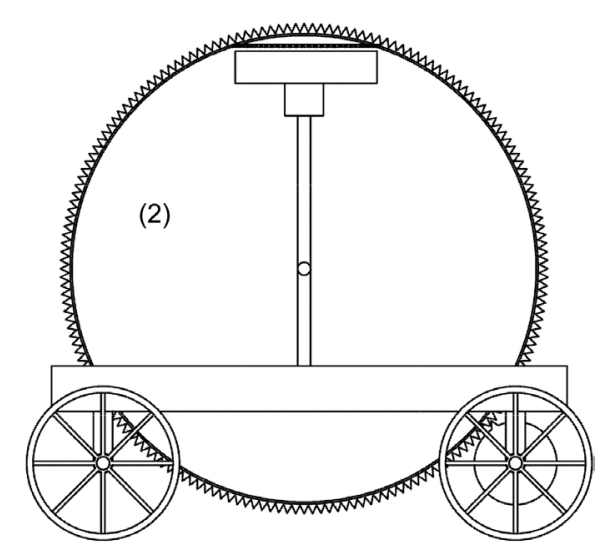

Top-view

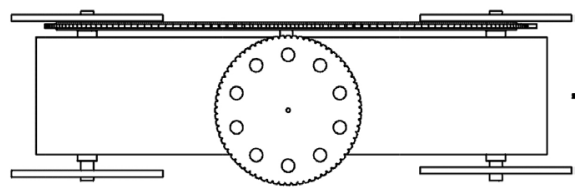

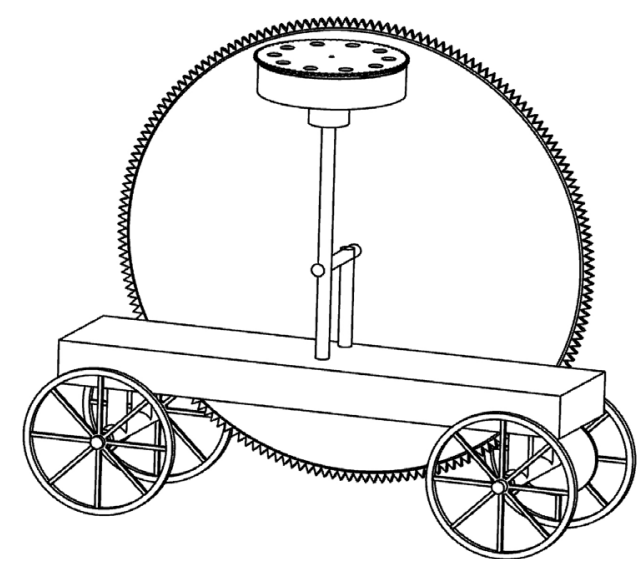

Figure 4. Sketch of Vitruvius' odometer (a 180 teeth gear is represented for sake of readability).

On the wheel (3) in correspondence to each tooth there is a hole that contains a pebble while the lower face of the wheel is in contact with a container that has a single hole: in this way at every mile travelled a pebble falls into the container, allowing to measure the number of miles travelled during the day.

Figure 3 presents a CAD reconstruction of the Vitruvius' odometer realized by the authors according to the hypotheses of Schofield (2016), but it must be said that different alternatives are also possible, especially as regards the orientation and positioning of the 400 teeth vertical disk (2), about which Vitruvius does not provide further information. Figure 5, for example, shows the reconstruction of Sleeswyk (1981). 

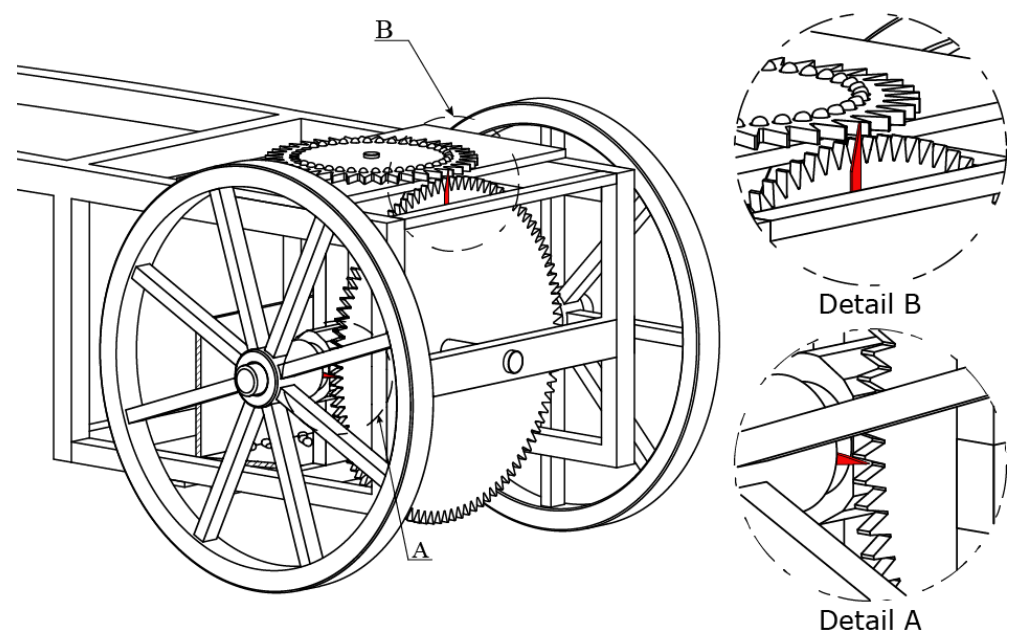

Figure 5. Reconstruction of Vitruvius' odometer according to Sleeswyk (1981) (a 100 teeth gear is represented for sake of readability).

\section{Leonardo's Odometer}

Leonardo's study of the Vitruvius machine led to the three drawings of folio 1r, shown here in Figure 6. The mechanism shown on the right is meant to signal that a certain distance has been travelled, while the central drawing and the one on the left represent two odometers.

Leonardo, who was left-handed, probably first designed the one-wheel odometer sketched in the center, whose operation faithfully reflects the mechanism described by Vitruvius, being based on the meshing of a one-tooth gear; there is no comment for such machine.

The drawing on the left, on the other hand, probably represents a redesign of the original concept carried out by Leonardo to overcome the most significant construction difficulties. In fact Leonardo widely explains the operation of the left odometer, strangely using the writing from left to right instead of writing in reverse, as usual for him.

Leonardo, despite having lived in different places, probably used the units of measurement in the Florence district to design the odometer; this can be deduced both from the comments on folio $1 \mathrm{r}$ where the odometer is drawn, and because this dates back to the period in which Leonardo had returned to Florence. At that time one mile corresponded to $3000 \mathrm{arms}$, and one arm to 583.6 $\mathrm{mm}$; therefore one mile measured $1750.8 \mathrm{~m}$.

The odometer is mounted on a two wheels cart carried by a horse, see Figure 7, because probably Leonardo did not know what a "raeda" was. The wheels have a circumference of 10 arms: therefore the odometer has travelled a Florentine mile, which corresponds to $3000 \mathrm{arms}$, when the wheels have completed 300 turns. Referring to Figure 8, on the axle of the wheels (a) there is a short section of thread (detail B) that mates with a gear wheel (m) mounted on a longitudinal shaft (b): for each revolution of the axle this wheel shifts just one tooth. Since this wheel has 300 teeth, when it has rotated one turn the odometer has travelled 3000 arms, or 1 mile. 


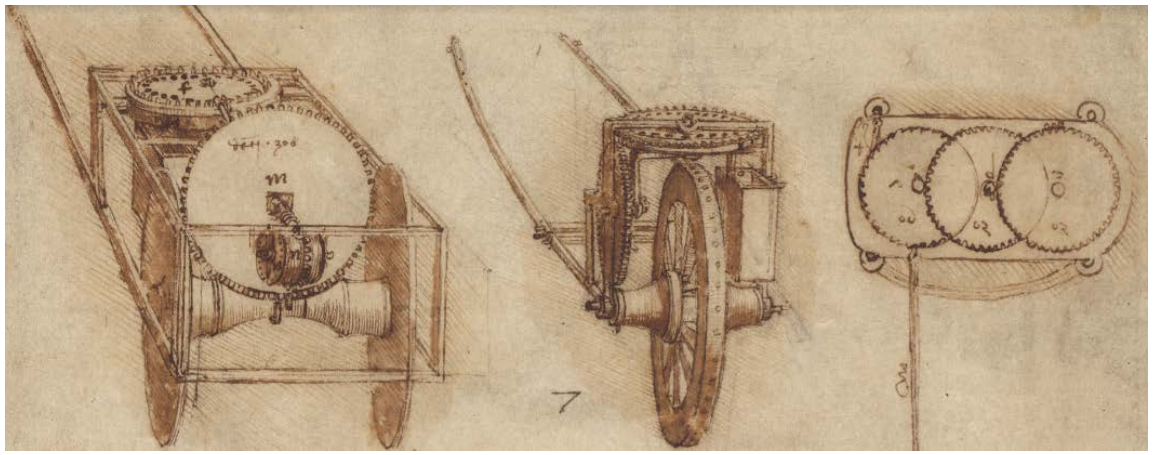

Figure 6. Design of the odometer by Leonardo da Vinci in folio 1r-b of the Codex Atlanticus.

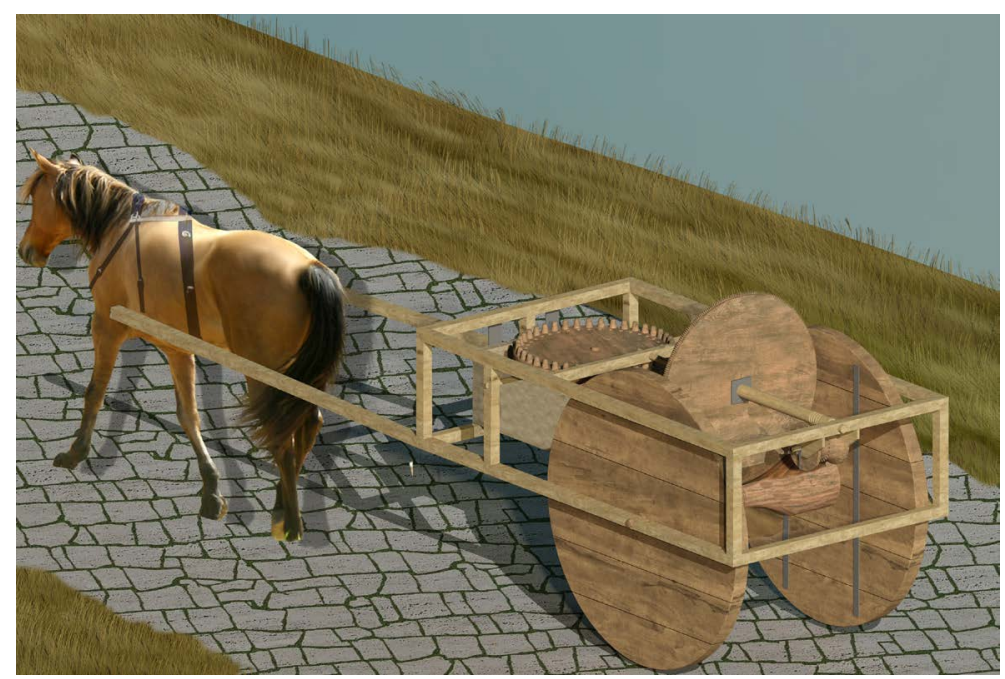

Figure 7. Digital reconstruction of Leonardo's odometer.
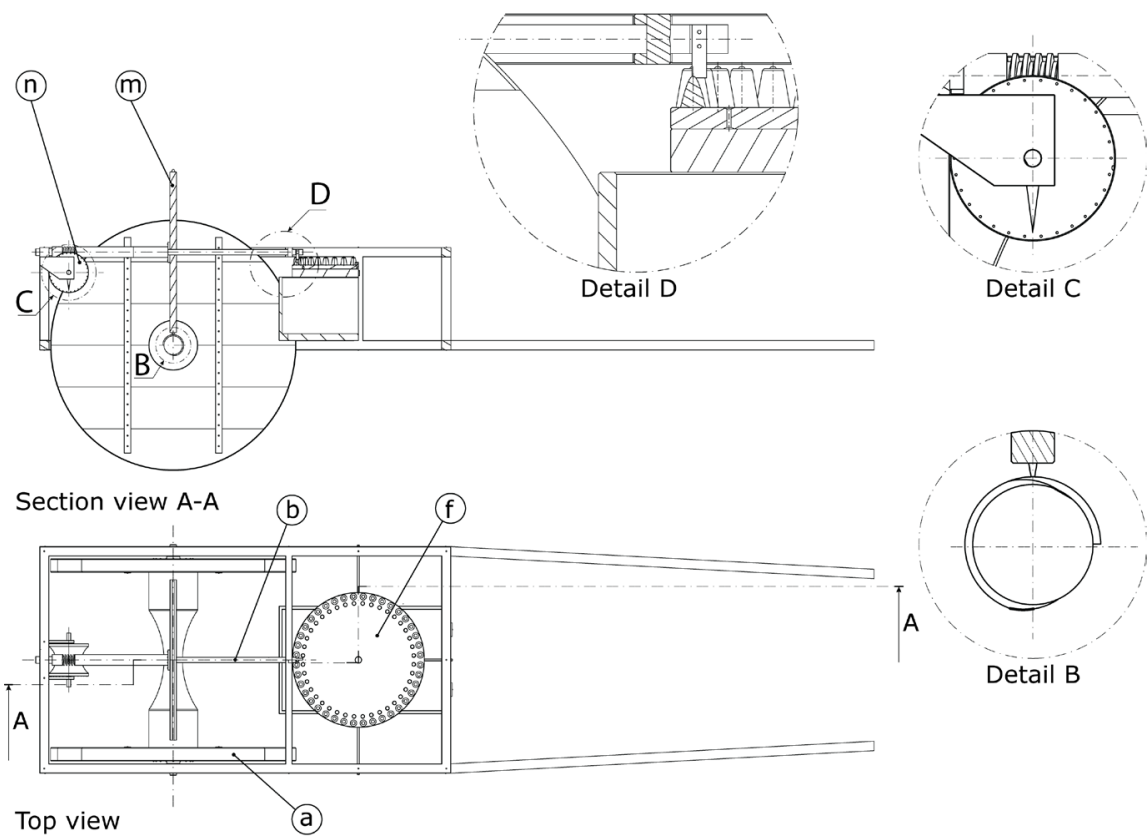

Figure 8. Sketch of the odometer by Leonardo da Vinci. 
The longitudinal shaft (b) is also connected with a horizontal wheel (f) placed at the front end of the machine, Figure 9; the end of the shaft has a tooth which mates with a series of pegs fixed along the circumference of the wheel (f) (see detail $\mathrm{D}$ ): at each complete rotation of the shaft, which corresponds to the distance of 1 mile, the tooth shifts the wheel of one peg. The wheel has a hole, which houses a pebble, in correspondence of each peg; the lower face of the wheel is in contact with a fixed drum which has just one hole: in this way when the odometer has travelled one mile a pebble falls into the container, allowing to measure the number of miles travelled during the day, Figure 10.

Leonardo's odometer has an additional gear wheel (n). This is driven through a worm gear (detail C) by the same shaft (b) that moves the wheel (f) and performs the same number of turns as the latter, thus providing a visual feedback of the route travelled through a pointer, Figure 11.

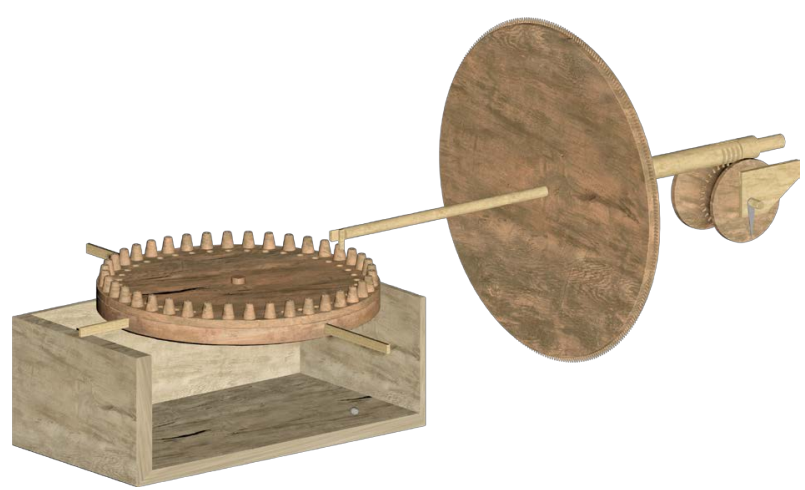

Figure 9. Longitudinal shaft and the two mileage counting systems.

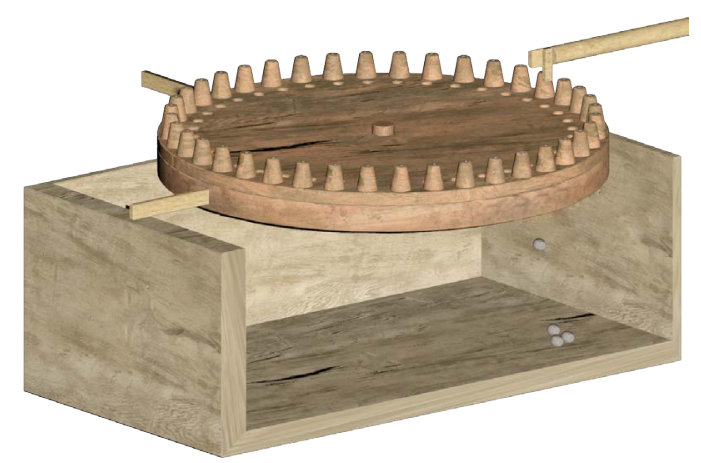

Figure 10. Peg wheel and drum with pebbles.
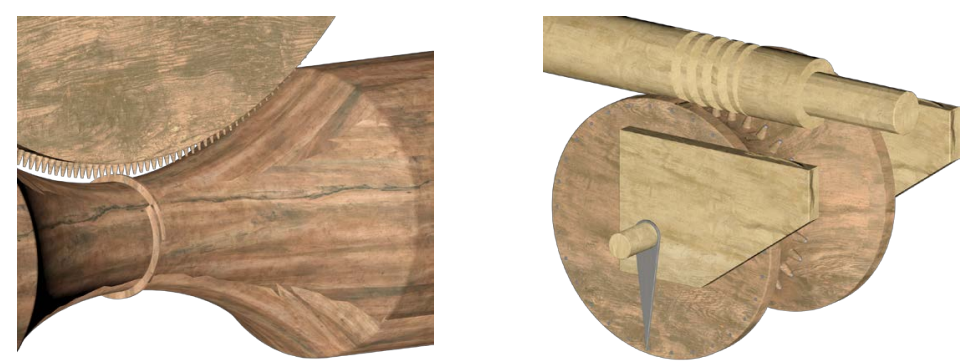

Figure 11. Use of the worm gear in the odometer of Leonardo da Vinci. 


\section{Comparison between the Two Designs}

Comparing Leonardo's work with the interpretations of Vitruvius by various authors (e.g. Frà Giocondo, Cesariano and Barbaro) it is noted that Leonardo followed closely the same conceptual procedure of Vitruvius for the functional design of the odometer: first the size of the cart wheels is defined, then the characteristics of the transmission are chosen and finally the system for counting the travelled miles is described.

A first difference between the two works lies in the value used for the constant $\pi$, when calculating the diameter of the cart wheels. According to Vitruvius the wheels must have a diameter of 4 feet and a circumference of 12.5 feet for which a value $\pi=3.125$ was evidently used; Leonardo, on the other hand, uses the value $\pi=(3+1 / 7)=3 . \overline{142857}$ closer to the real value. Therefore the odometer of Vitruvius would commit an error of 2654.8 feet (equal to $786.89 \mathrm{~m}$ ) in the measurement of 100 Roman miles (with an error of about $0.5 \%$ ) while that of Leonardo, more precise, would overestimate the distance of 100 Florentine miles by 120 arms (equivalent to $70 \mathrm{~m}$ ) (with an error less than one tenth of the previous one).

The greatest difference in the concepts of the two scientists lies in the transmission. Vitruvius "reduced" the 400 turns of rotation of cart wheels into a single rotation of a shaft by using the coupling between a wheel with a single tooth and a gear wheel with 400 teeth. However, this necessarily implies that the diameter of the gear wheel is 400 times larger than the diameter of the wheel with a single tooth: a gear made in this way would have been difficult to realize in practice due to the large dimensions and therefore to the weights of the members making up the system. Sleeswyk [6] suggests the possibility that Vitruvius with the terminology "drum equipped with a single tooth protruding from its circular surface" referred to a worm: if this were correct the size of the system would be much more compact simplifying its realization.

Leonardo, on the other hand, chose to reduce the 300 revolutions of the cart wheel necessary to travel a mile through a one-principle worm screw coupled to a toothed wheel with 300 teeth, which can be more easily realized. In addition, Leonardo mounted the second single tooth meshing with the last horizontal wheel, on the axis of the vertical gear wheel. In this way the tooth rotated on a very small radius, so that the depth of the gear had a realistic value.

It should be also noted that Leonardo probably tackled the problem of positioning the intermediate gear wheel with 400 teeth, about which Vitruvius only says that it lies on a vertical plane: therefore the two solutions reported in the Atlantic Code explore the two possible orientations (Figure 6 left and center).

In the end, there are still unsolved questions too. For example, it is not clear why Leonardo decided to make the second pointer device that provides visual feedback of the route travelled. Moreover, it is not known why Leonardo used a gear with a transmission ratio of 1:300 instead of using a 2-stage gearbox: he may have done it to track the path travelled by Vitruvius. 


\section{The Influence of Archimedes}

Previous paragraphs have shown that the concept of Vitruvius had several flaws, e.g. the large wheel with 400 teeth that could well have been replaced by a two stage gearing with a 1:20 ratio each. This is strange because Vitruvius was an experienced engineer and all his work was addressed to solve practical problems while in this case the odometer was probably never built.

Sleeswyk (1981) suggests that the odometer could have been invented by Archimedes instead and just reported by Vitruvius in the De Architectura. In fact the concept of leaving a pebble drop to set the passing of time is indisputably due to Archimedes who used it in several inventions, first of all the famous water clock. Moreover Archimedes is the inventor of the worm screw that we saw is fundamental to odometer functionality. In the end, Sleeswyk brings also historic arguments to his thesis: when Archimedes was a promising young scientist, the Romans experienced the maximum expansion efforts and needed new routes to be built. Archimedes was probably a relative of Hieron II, the tyrant of Syracuse in Sicily and in the end allied with Romans during the first Punic War: in this period the Romans built about 750 kilometers of new routes, that needed the pose of milestones during the way, and Archimedes could well have helped them measuring the distances.

\section{Conclusion}

The study of the writings of Vitruvius and Leonardo tells us how the liaisons between the two scholars were strong despite the 1500 years that separate them. Leonardo was fascinated by the work of Vitruvius and has been looking for a copy of "De Architectura" for many years. The exhibition in Fano (July 12-Oct. 13 , 2019) has shown how much Vitruvius influenced Leonardo's work. As for the odometer, Leonardo tried to draw the original concept by Vitruvius in the central drawing of folio 1r-b of the Codex Atlanticus (Figure 6) but probably gave up understanding it was practically impossible to realize. In fact the teeth of gear wheels in past years had the shape of equilateral triangles as shown for example in the Antikythera gearwheels and a 1:400 gear ratio causes a too large diameter or too small teeth, as would happen todays too with current design criteria. Leonardo overcame the problem in his design (see the left of Figure 6) by using a worm gear and a single tooth meshing with a peg wheel.

It is strange, however, that a practical and experienced engineer as Vitruvius had not taken into consideration this aspect of the design. Sleeswyk suggests that Vitruvius never built the odometer but simply described an invention dated back to Archimedes of Syracuse, who lived and cooperated with the Romans when they built some 750 kilometers of roads. In this case, the sentence "drum equipped with a single tooth protruding from its circular surface" would refer to a worm, that Archimedes well knew. In this way the odometer would connect three giants of the past: Archimedes, Vitruvius and Leonardo. 


\section{Acknowledgements}

The research has been partly developed with Sistema Museo (Perugia, Italy) and Stark (Cagli, Italy) for the preparation of the exhibition "Leonardo e Vitruvio: oltre il cerchio e il quadrato", Fano (I), 2019, under the supervision of Francesca Borgo and Paolo Clini. Part of this work has been presented at the 3rd International Conference of IFToMM Italy and has been referenced in (Callegari et al., 2021).

\section{Conflicts of Interest}

The authors declare no conflicts of interest regarding the publication of this paper.

\section{References}

Borgo, F. (2019). Leonardo legge Vitruvio. In Leonardo e Vitruvio: Oltre il cerchio e il quadrato (pp. 23-39). Venice: Marsilio.

Brillarelli, S., Callegari, M., Carbonari, L., \& Clini, P. (2020). Digital Experience of the Work of Vitruvius and Leonardo. IOP Conference Series: Materials Science and Engineering, 949, Article ID: 012041. https://doi.org/10.1088/1757-899X/949/1/012041

Callegari, M., Brillarelli, S., \& Scoccia, C. (2021). The Odometers of Marcus Vitruvius Pollio and Leonardo da Vinci. Mechanisms and Machine Science, 91, 75-82. https://doi.org/10.1007/978-3-030-55807-9 9

Ceccarelli, M., \& De Paolis, P. (2008). A Survey on Roman Engineers and Their Machines. In Proceedings of the III Congreso Internacional de Patrimonio e Historia de la Ingenieria (pp. 29-48). Las Palmas de Gran Canaria: Centro Internacional de Conservacion de Patrimonio.

Chondros, T. G. (2007). Archimedes (287-212 BC). In M. Ceccarelli (Ed.), Distinguished Figures in Mechanism and Machine Science (pp. 1-30). History of Mechanism and Machine Science, Vol. 1, Dordrecht: Springer. https://doi.org/10.1007/978-1-4020-6366-4_1

Chondros, T. G. (2009). The Development of Machine Design as a Science from Classical Times to Modern Era. In H. S. Yan, \& M. Ceccarelli (Eds.), International Symposium on History of Machines and Mechanisms (pp. 59-68). Dordrecht: Springer. https://doi.org/10.1007/978-1-4020-9485-9 5

Chondros, T. G. (2010). Archimedes Life Works and Machines. Mechanism and Machine Theory, 45, 1766-1775. https://doi.org/10.1016/j.mechmachtheory.2010.05.009

Cigola, M., \& Ceccarelli, M. (2014). Marcus Vitruvius Pollio (Second Half of the Ist Century B.C.). History of Mechanisms and Machine Science, 26, 307-344. https://doi.org/10.1007/978-94-017-8947-9 15

Cigola, M., \& Ceccarelli, M. (2016). Machine Designs and Drawings in Renaissance Editions of de Architectura by Marcus Vitruvius Pollio. History of Mechanisms and Machine Science, 31, 291-307. https://doi.org/10.1007/978-3-319-22680-4 17

De Solla Price, D. J. (1974). Gears from the Greeks. The Antikythera Mechanism: A Calendar Computer from ca. 80 B.C. Transactions of American Philosophical Society, New Series, 64, 19. https://doi.org/10.2307/1006146

Dimarogonas, A. D. (1991). The Origins of the Theory of Machines and Mechanisms. Proceedings 40 Years of Modern Kinematics: A Tribute to Ferdinand Freudenstein Con- 
ference, Minneapolis.

Needham, J. (1965). Physics and Physical Technology, Part 2, Mechanical Engineering. Science and Civilisation in China (Vol. 4). Cambridge: Cambridge University Press.

Oliveira, A. R. E. (2019). The Mechanical Sciences in Leonardo da Vinci's Work. Advances in Historical Studies, 8, 215-238. https://doi.org/10.4236/ahs.2019.85016

Rosheim, M. E. (2006). Leonardo’s Lost Robots. Dordrecht: Springer.

Rossi, C., Ceccarelli, M., \& Cigola, M. (2011). La Groma, lo Squadro agrimensorio e il corobate. Note di approfondimento su progettazione e funzionalità di antiche strumentazioni, Disegnare Idee Immagini, anno XI n. 42, 22-33.

Scaglia, G. (1992). Francesco Di Giorgio: Checklist and History of Manuscripts and Drawings in Autographs and Copies from Ca. 1470 to 1687 and Renewed Copies. Bethlehem: Lehigh Univ Pr.

Schofield, R. V. (2016). Notes on Leonardo and Vitruvius. In C. Moffatt, \& S. Taglialagamba (Eds.), Illuminating Leonardo (Vol. 1, pp. 120-133). Leiden: Brill. https://doi.org/10.1163/9789004304130 011

Sleeswyk, A. W. (1981). Vitruvius' Odometer. Scientific American, 245, 188-200. https://doi.org/10.1038/scientificamerican1081-188

Sorge, F. (2012). Coupling Mechanics of Antikythera Gearwheels. Journal of Mechanical Design, 134, Article ID: 061007. https://doi.org/10.1115/1.4006530

Taddei, M., Zanon, E., \& Laurenza, D. (2005). Leonardo's Machines. Secrets and Inventions in the Da Vinci Codices. Milano: Giunti.

Vitruvius (1990). De Architectura. Translation by Luciano Migotto (Latin and Italian), Rome: Edizioni Studio Tesi.

Wright, M. T. (2005). The Antikythera Mechanism: A New Gearing Scheme. Bulletin of the Scientific Instrument Society, 85, 2-7. 